$\xi=-1$

\title{
Numerical simulation of the fire resistance of composite slabs with steel deck
}

\author{
Paulo A. G. Piloto ${ }^{*}$, Lucas M.S. Prates², Carlos Balsa ${ }^{3}$, Ronaldo Rigobello ${ }^{2}$ \\ ${ }^{1}$ LAETA-INEGI, Department of Applied Mechanics, Polytechnic Institute of Bragança (IPB), Portugal \\ ${ }^{2}$ Federal Technological University of Paraná (UTFPR), Brazil \\ ${ }^{3}$ Department of Mathematics, Polytechnic Institute of Bragança (IPB), Portugal \\ *Corresponding author E-mail: ppiloto@ipb.pt
}

\begin{abstract}
This investigation is related with the fire resistance of composite slabs with steel deck. This composite solution consists of a concrete topping cast on the top of a steel deck. The concrete is typically reinforced with a steel mesh and may also contain individual rebars. The deck also acts as reinforcement and may be exposed to accidental fire conditions from the bottom. This composite solution is widely used in every type of buildings and requires fire resistance, in accordance to regulations. The fire resistance is specified by the loadbearing capacity (R), insulation (I) and integrity (E). The fire rating for (R) and (E) is not in the scope of this investigation. The fire rating for insulation (I) is evaluated by two different methods (numerical simulation and simple calculation). The fire rating is calculated for 32 different geometric configuration, in order to evaluate the effect of the thickness of the concrete layer and the thickness of steel deck. The fire resistance (I) increases with the thickness of the concrete when using both methods, but the simple calculation method seems to be unsafe for all the cases, requiring a revision for the formulae presented in Annex D of EN1994-1-2. A new proposal is presented.
\end{abstract}

Keywords: Composite slabs; Fire resistance; Numerical simulation; Simple calculation method.

\section{Introduction}

Concrete slabs with steel decks are slabs that use steel deck as a permanent formwork and as reinforcement to the concrete placed on top, see Figure 1. This represents one of the advantages of this solution, because reduces the construction time, requires less concrete, providing slender slabs.

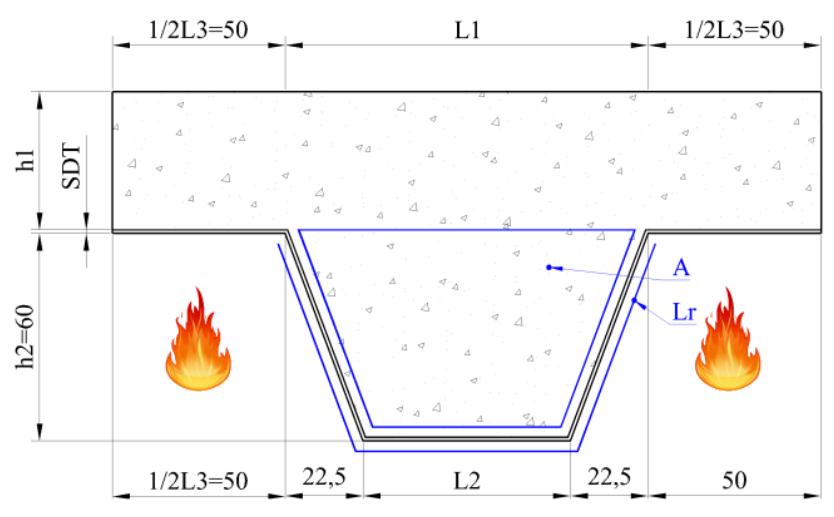

Fig. 1: Definition of the rib geometry for the cross section of part of the composite slab. L3 is the dimension of the upper flange, $\mathrm{Lr}$ is the exposed area of the rib per metre of rib length, $\mathrm{A}$ is the concrete volume of the rib per metre of rib length, h2 is the concrete part within the decking. Parameters: h1 is the concrete depth above the deck, SDT is the steel decking thickness and L1 is the length between upper flanges and L2 is the dimension of the lower flange.
The use of these composite slabs in buildings has become very popular, since 1980 . The overall depth $(\mathrm{h} 1+\mathrm{h} 2)$ can vary between 100 to $170 \mathrm{~mm}$. The thickness of the deck can vary from 0.7 to 1.2 or more and this part of the structure is normally galvanized to increase durability [1]. The composite floor is usually made with these plate elements supported by secondary beams (linear elements) and shear studs that are responsible for the composite action between both elements. The fire resistance of both elements is prescribed by the building codes, but this investigation only considers the fire behaviour of the plate element.

Several studies have been conducted to evaluate the fire resistance of concrete slabs with steel deck. In 1990 Hamerlinck et al [2] developed a numerical model that satisfactorily predicted the fire behaviour of different slab geometries. In 1999 Bailey et al [3] presented the results of 2 experimental full-scale tests (complete building), demonstrating that the performance of the structure under fire differed from that was expected from fire codes and demonstrated that they were also conservative. Both tests also demonstrated that the element behaviour is different from what is normally obtained from standard small-scale fire tests. In $2001 \mathrm{~S}$ Lamont et al [4], performed an analysis of the heat transfer in composite slabs of the Cardington building. Four tests were performed in different floors of the building. An adaptive heat transfer model was used to estimate the temperatures through the slab. The developed model presented satisfactory results for most of the tests. More recently in 2017, Guo-Qiang Li et al [5], performed 4 tests in composite slabs with steel decking, which were fire rated with 90 minutes and concluded that Eurocode 4 design calculations are conservative and that could be used for the other geometries, beyond the specified limit. The experiments were developed at Tongji University and the average temperatures of the furnace were below the standard ISO 834 [6]. The temperature at the bot- 
tom of the slabs (above the steel deck) were $100{ }^{\circ} \mathrm{C}$ on average below furnace temperature. The temperature on the unexposed surface was less than $100^{\circ} \mathrm{C}$ during the tests, being the fire rating determined by stability. This research also presents summary of previous experiments developed on composite floor systems.

\section{Fire in composite slabs}

Composite slabs need to meet fire-safety requirements according to building codes. The fire requirements are normally specified by fire rating periods of $30,60,90$ minutes or more. The fire assessment of this type of elements is normally made using standard fire tests $[6,7,8]$ and should take into account criterion for stability $(\mathrm{R})$, insulation (I) and Integrity (E). These tests are expensive and time-consuming, reason why the fire resistance can be evaluated by means of numerical simulation or by the use of simple calculation methods. The fire behaviour of composite slabs is generally defined with respect to standard fire exposure from below. Fire exposure at the other side of the slab is less critical [1].

The European recommendations for composite steel/concrete slabs were introduced by the ECCS [9] and a proposal for the assessment of the insulation criterion (I) was made, based on the calculation of the effective thickness of concrete. At this stage, conservative assumptions have been used, leading to uneconomic solutions [1].

The current version of Eurocode 4 [10] proposes a simple calculation method, in annex D, to define the fire resistance (I), which depends linearly in a set of geometric parameters, but that seems to be over conservative as well.

To prevent fire propagation into adjacent compartments, slabs must meet the requirements for fire resistance, preventing the propagation of fire and limiting the temperature of the unexposed surface in the fire compartment. The insulation criterion (I) for fire resistance of this construction element depends on the temperature evolution at the unexposed surface. The performance level used to define insulation shall be the average temperature rise on the unexposed surface limited to $140{ }^{\circ} \mathrm{C}$ above the initial average temperature, or, with the maximum temperature rise at any point limited to $180{ }^{\circ} \mathrm{C}$ above the initial average temperature [7]. A temperature increase of $140{ }^{\circ} \mathrm{C}$ at the unexposed side is usually taken as the limiting insulation criterion [9], but the other condition for the maximum temperature can also be a limiting condition.

For concrete slabs with steel decks, the integrity criterion (E) is easily verified, because concrete slab is cast in situ, assuring that joints are correctly sealed. Possible cracks that may occur during the tests due to fire exposure are protected by the steel deck, preventing the penetration of flames and hot gases through the slab.

\section{Numerical simulation}

Only the rib part of the slab is meshed to solve a nonlinear transient thermal analysis. The finite element method requires the solution of equation (1) in the domain of the cross section, $(\Omega)$ and equation (2) in the boundary exposed to fire $(\partial \Omega)$.

$$
\begin{aligned}
& \nabla\left(\lambda_{(T)} \cdot \nabla T\right)=\rho_{(T)} \cdot C p_{(T)} \cdot \partial T / \partial t \quad(\Omega) \\
& \lambda_{(T)} \cdot \nabla T \cdot \vec{n}=\alpha_{c}\left(T_{g}-T\right)+\phi \cdot \varepsilon_{m} \cdot \varepsilon_{f} \cdot \sigma \cdot\left(T_{g}^{4}-T^{4}\right)
\end{aligned}
$$

In these equations: $T$ represents the temperature of each material; $\rho_{(T)}$ defines the specific mass; $C p_{(T)}$ defines the specific heat; $\lambda_{(T)}$ defines the thermal conductivity; $\alpha_{c}$ specifies the convection coefficient; $T_{g}$ represents the gas temperature of the fire compartment, using standard fire ISO 834 [6] to be applied to the lower part of the slab, $\phi$ specifies the view factor; $\varepsilon_{m}$ represents the emissivity of each material (in both cases equals 0.7 ); $\varepsilon_{f}$ specifies the emissivity of the fire; $\sigma$ represents the StefanBoltzmann constant.
The numerical model uses a 2D finite element (PLANE55) with four nodes and one degree of freedom per node (temperature). The interpolating functions are linear. The time increment is typically $60 \mathrm{~s}$, with the possibility to be reduced to $1 \mathrm{~s}$. The convergence criterion is based on the heat flow calculation, for a reference value of $10^{-6}$ and a tolerance value of $0.1 \%$.

The model uses quadrilateral finite elements to mode the steel deck and the concrete part, see Figure 2. The parametric analysis uses 4 different values for the steel deck (SDT= 0.7, 0.8, 1.0 and $1.2 \mathrm{~mm}), 2$ different values of geometry L1/L2 $(84,40 \mathrm{~mm} / \mathrm{mm})$ and $\mathrm{L} 1 / \mathrm{L} 2(105 / 60 \mathrm{~mm} / \mathrm{mm})$ and 8 different values for concrete depth above the deck $(\mathrm{h} 1=40,50,60,70,80,90,100$ and $110 \mathrm{~mm})$. All the other dimensions remain fixed.

An initial uniform temperature is applied to all the nodes $\left(20^{\circ} \mathrm{C}\right)$. The lower part of the deck is submitted to standard fire conditions, using a convection coefficient of $25\left[\mathrm{~W} / \mathrm{m}^{2} \mathrm{~K}\right]$ and an emissivity of the fire equal to 1 . The upper part of the slab is submitted to a convective coefficient of $9\left[\mathrm{~W} / \mathrm{m}^{2} \mathrm{~K}\right]$ to include the radiation effect as well [11].

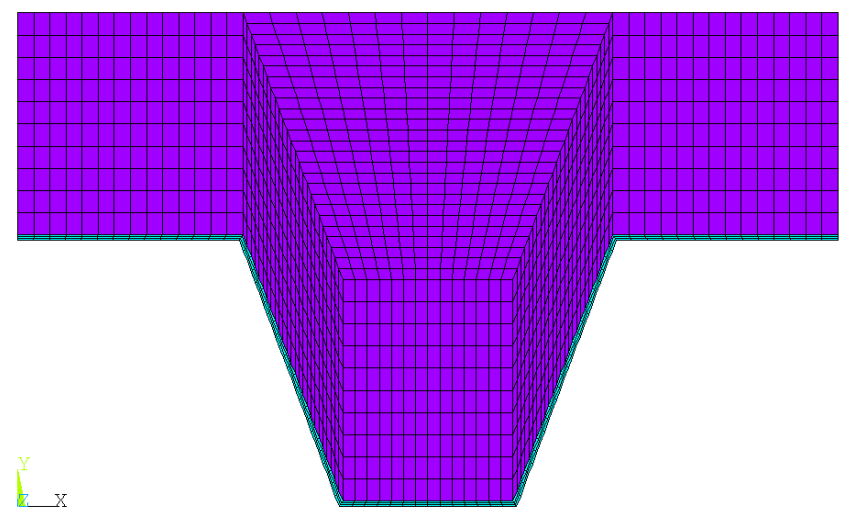

Fig. 2: Finite element mesh used for the rib geometry of the slab (L1/L2=84/40 mm/mm, h1=50 mm, SDT=1.2mm)

Material properties are temperature dependent and vary according the standards used for composite, steel and concrete $[10,12,13]$. Both properties are depicted in figure 3 and figure 4 . The conductivity of the steel decreases with temperature and the specific heat has a strong variation due to the allotropic phase transformation. The specific mass and the conductivity of the concrete decrease with temperature, being the upper value used for these simulations. The specific heat of concrete presents an increase with a peak value related with $3 \%$ in moisture content of concrete weight.

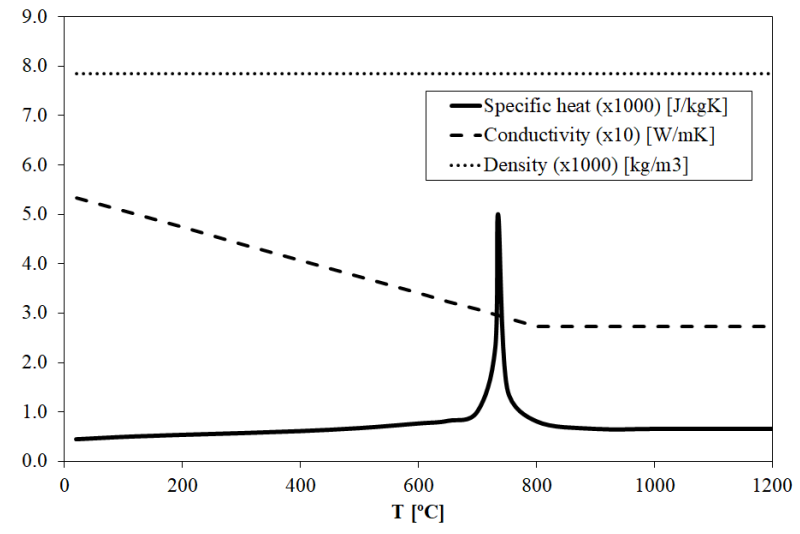

Fig. 3: Thermal properties for carbon steel. 


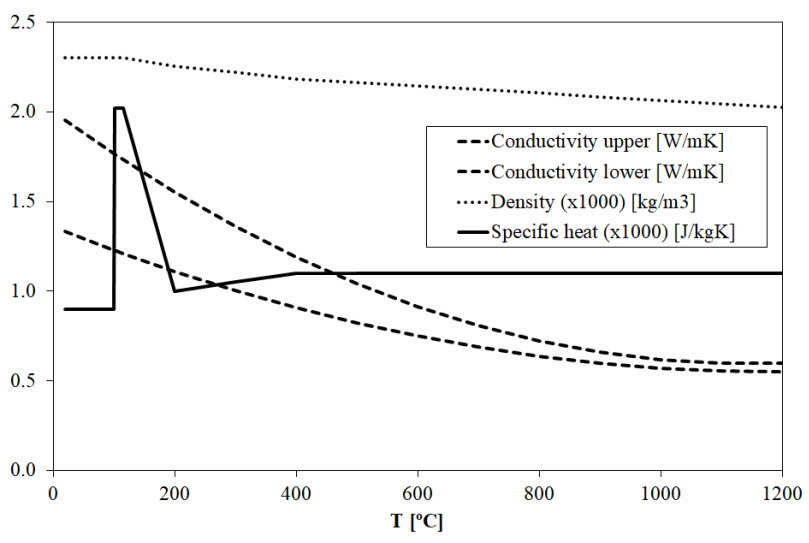

Fig. 4: Thermal properties for concrete.

Temperature is predicted in the model for a total time of simulation that is able to assure the prediction of fire resistance in accordance to the criteria. The weighted average temperature and the maximum temperature are calculated on the unexposed side of the slab and compared to the criteria to achieve the fire resistance (Insulation), see figure 5 for an example of the temperature field at the critical time ( $\mathrm{t}=31$ minutes). Maximum temperature in the unexposed surface is always expected to be aligned with the region corresponding to the upper flange.

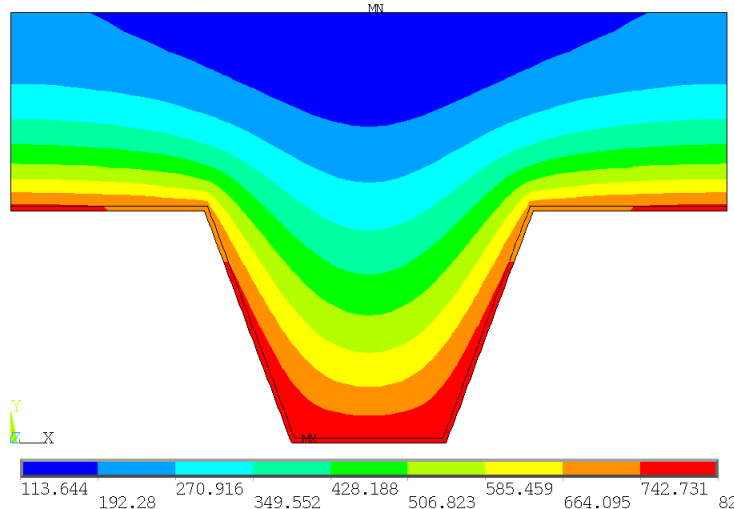

Fig. 5: Temperature results for the critical time, for the rib geometry $(\mathrm{L} 1 / \mathrm{L} 2=84 / 40 \mathrm{~mm} / \mathrm{mm}, \mathrm{h} 1=50 \mathrm{~mm}, \mathrm{SDT}=1.2 \mathrm{~mm})$.

The weighting factors considered are $l_{1}$ and $l_{3}$. The fire resistance is presented in completed minutes, see table 1 . The results are independent of the steel deck thickness.

Table 1: Fire resistance in completed minutes (insulation criterion).

\begin{tabular}{lccccccccc}
\hline Geometry & $\mathrm{h} 1[\mathrm{~mm}]$ & 40 & 50 & 60 & 70 & 80 & 90 & 100 & 110 \\
\hline $\mathrm{L} 1 / \mathrm{L} 2=84 / 40$ & $t_{i}[\mathrm{~min}]$ & 22 & 31 & 41 & 51 & 63 & 76 & 91 & 107 \\
$\mathrm{~L} 1 / \mathrm{L} 2=105 / 60$ & $t_{i}[\mathrm{~min}]$ & 22 & 31 & 42 & 55 & 67 & 81 & 96 & 112
\end{tabular}

Figure 6 represents the temperature evolution in the unexposed surface of the slab, for different values of concrete depth above the deck (h1), for one specific steel deck thickness (SDT=1.2 mm) and for two different geometries (L1/L2 $=84 / 40$ and $\mathrm{L} 1 / \mathrm{L} 2=105 / 60)$. For smaller concrete depth the maximum temperature (TMAX) criterion is used as limiting condition to define the fire resistance time. For higher concrete depth, the average temperature (TAVE) evolution is used as limiting condition to define the fire resistance. Similar results were obtained for the other steel deck thicknesses.

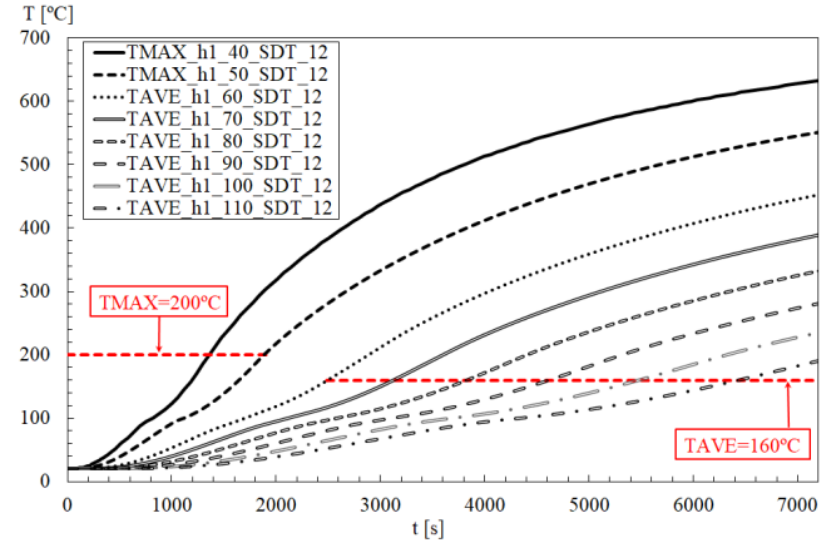

Fig. 6a: Unexposed temperature evolution (TMAX or TAVE). (L1/L2=84/40 $\mathrm{mm} / \mathrm{mm}, \mathrm{SDT}=1.2 \mathrm{~mm})$.

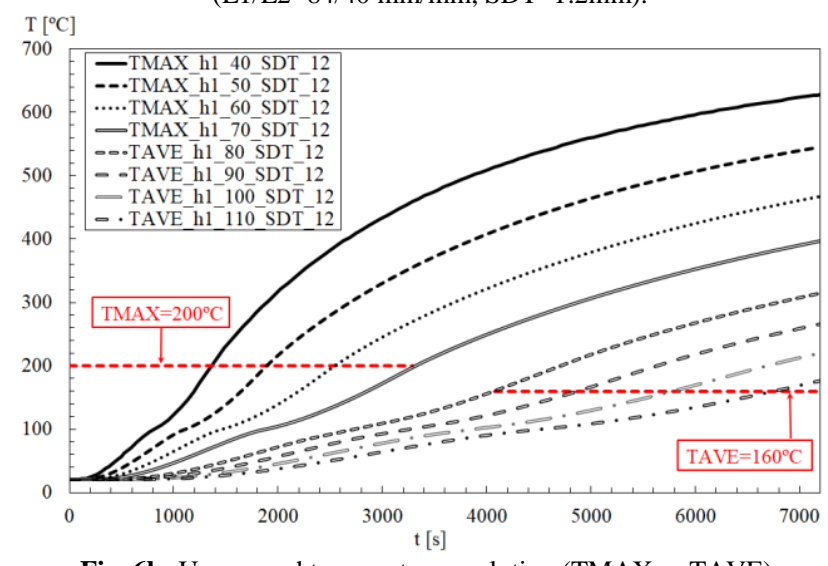

Fig. 6b: Unexposed temperature evolution (TMAX or TAVE). $(\mathrm{L} 1 / \mathrm{L} 2=105 / 60 \mathrm{~mm} / \mathrm{mm}, \mathrm{SDT}=1.2 \mathrm{~mm})$.

\section{Simple calculation method}

According to annex D of Eurocode 4 [10], the fire resistance $t_{i}$, of both simply supported and continuous concrete slabs with profiled steel decks, when submitted to standard fire, is calculated according to equation (3).

$$
\begin{aligned}
& t_{i}=a_{0}+a_{1} \cdot h_{1}+a_{2} \cdot \phi+a_{3} \cdot A / L_{r}+a_{4} \cdot 1 / l_{3}+a_{5} \cdot A / L_{r} 1 / l_{3} \\
& A / L_{r}=h_{2}\left(l_{1}+l_{2}\right) / 2 /\left[l_{2}+2 \sqrt{h_{2}^{2}+\left(\left(l_{1}-l_{2}\right) / 2\right)^{2}}\right]
\end{aligned}
$$

The partial factors $a_{i}$ are proposed for normal weight concrete (NC), according to table 2 .

Table 2: Partial factors used for the calculation of fire resistance (NC).

\begin{tabular}{llllll}
\hline $\mathrm{a} 0$ & $\mathrm{a} 1$ & $\mathrm{a} 2$ & $\mathrm{a} 3$ & $\mathrm{a} 4$ & $\mathrm{a} 5$ \\
{$[\mathrm{~min}]$} & {$[\mathrm{min} / \mathrm{mm}]$} & {$[\mathrm{min}]$} & {$[\mathrm{min} / \mathrm{mm}]$} & {$[\mathrm{min} . \mathrm{mm}]$} & {$[\mathrm{min}]$} \\
\hline-28.8 & 1.55 & -12.6 & 0.33 & -735 & 48 \\
\hline
\end{tabular}

The results are also independent of the steel deck and present a linear dependence on concrete depth above the deck h1, see table 3 .

Table 3: Fire resistance in completed minutes (insulation criterion).

\begin{tabular}{llllllllll}
\hline Geometry & $\mathrm{h} 1[\mathrm{~mm}]$ & 40 & 50 & 60 & 70 & 80 & 90 & 100 & 110 \\
\hline L1/L2 $=84 / 40$ & $t_{i}[\mathrm{~min}]$ & 34 & 50 & 65 & 81 & 96 & 112 & 127 & 143 \\
$\mathrm{~L} 1 / \mathrm{L} 2=105 / 60$ & $t_{i}[\mathrm{~min}]$ & 38 & 53 & 69 & 84 & 100 & 115 & 131 & 146
\end{tabular}

\section{Comparison of results}

The results of both methods are compared with existing experimental results and with old recommendation to determine the fire resistance for the concrete slabs with steel decks. The fire resistance is plotted against the effective thickness in figure 7 . The 
effective thickness is an arithmetical average of the thickness that takes into account the shape of the slab, equation (5).

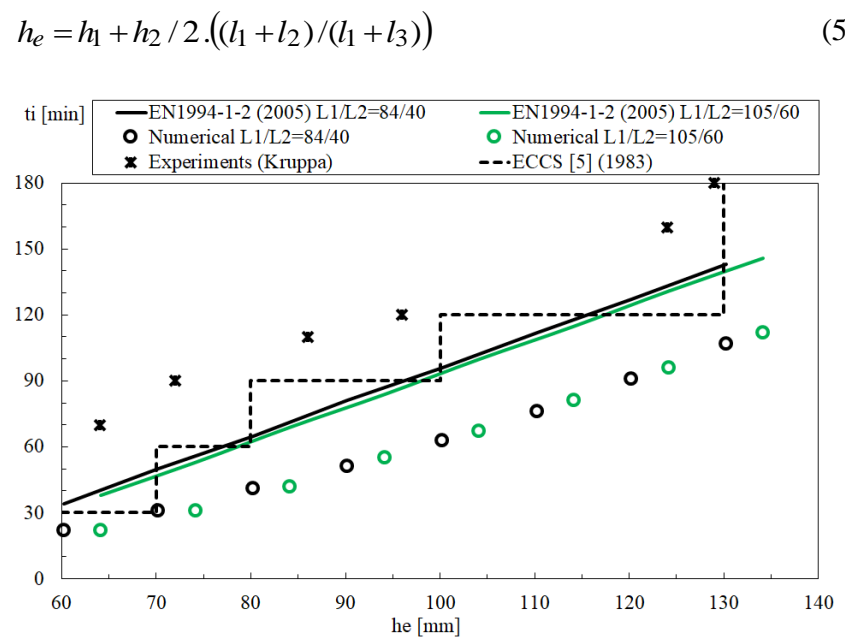

Fig. 7: Fire resistance for the effective thickness of the slab.

The fire resistance obtained by numerical simulation of all the cases is smaller in comparison with the other results. This means that the proposal from Eurocode 4 may be unsafe. According to the numerical results, there is a nonlinear dependence between the fire resistance and the effective thickness which is not included in equation (3). A quadratic dependence can be proposed to take this behaviour in to consideration, resulting a perfect correlation coefficient of 1 , equation (6).

$t_{i}=0.0058 . h_{e}^{2}+0.1071 . h_{e}-6.9976$

Numerical modelling of similar structural elements [4,14] demonstrate that experimental measured temperatures at the exposed surface during a fire are usually smaller than those resulting from numerical simulation. These researchers mention that this behaviour is probably caused by the buckling deformed shape of steel deck and also due to the debonding in the interface between the concrete and the steel deck, creating an extra insulation layer. These two facts may explain the lower experimental temperature values on the unexposed surface, which is the same to say higher fire resistance time in experiments.

\section{Conclusions}

The fire resistance of composite concrete slab with steel deck was determined using two different solution methods (numerical simulation method and simple calculation method). The numerical simulation predicts lower fire resistance (I) when compared to actual standards. This fire resistance, in most of the cases, was defined by the average temperature evolution, with an exception for smaller concrete depth below $60 \mathrm{~mm}$.

A new safer design formula is proposed to define the fire resistance for the geometric parameters used to characterize the concrete slabs with steel decks.

\section{References}

[1] Hamerlinck, A. F. The behaviour of fire-exposed composite steel/concrete slabs Eindhoven: Technische Universiteit Eindhoven DOI: 10.6100/IR348360, (1991). pp: 179.

[2] Hamerlinck, Ralph; Twilt, Leen; and Stark, Jan W. B., "A Numerical Model for Fire-exposed Composite Steel/concrete Slabs".10th International Specialty Conference on Cold-Formed Steel Structures, St. Louis, Missouri, U.S.A., October 23-24. (1990), pp. 115-130.

[3] Bailey, Colin \& Lennon, Tom \& Moore, D.B. "The behaviour of full-scale steel-framed building subjected to compartment fires". Structural Engineer. 77. (1999), pp. 15-21.
[4] S Lamont, A.S Usmani, D.D Drysdale, "Heat transfer analysis of the composite slab in the Cardington frame fire tests", Fire Safety Journal, Volume 36, Issue 8, ISSN 0379-7112, https://doi.org/10.1016/S0379-7112(01)00041-8, (2001), pp. 815839.

[5] Guo-Qiang Li, Nasi Zhang, Jian Jiang, "Experimental investigation on thermal and mechanical behaviour of composite floors exposed to standard fire", Fire Safety Journal, Volume 89, ISSN 0379-7112, https://doi.org/10.1016/j.firesaf.2017.02.009, (2017), pp. 63-76.

[6] ISO. ISO 834-1. Fire-resistance tests - Elements of building construction - Part 1: general requirements, Switzerland: Technical Committee ISO/TC 92, (1999). pp: 25.

[7] CEN. EN 1363-1: Fire resistance tests - Part 1: General Require ments. Brussels: CEN - European committee for standardization, (2012) pp. 52.

[8] CEN. EN 1365-2: Fire resistance tests for loadbearing elements Part 2: Floors and roofs. Brussels: CEN - European committee for standardization, (2014) pp. 34.

[9] ECCS. Calculation of the fire resistance of composite concrete slabs with profiled steel sheet exposed to the standard fire. ECCS, Committee T3-Fire safety of steel structures, technical note, Publication 32, (1983). pp: 48.

[10] CEN. EN 1994-1-2 - Eurocode 4: Design of Composite Steel and Concrete Structures - Part 1-2: General Rules-Structural Fire Design. Brussels: CEN - European committee for standardization (2005), pp. 109.

[11] CEN. EN 1991-1-2 - Eurocode 1: Actions on structures - Part 1-2: General actions - Actions on structures exposed to fire (pp. 59). Brussels: CEN - European Committee for Standardization (2002), pp: 59.

[12] CEN. EN 1993-1-2 - Eurocode 3: Design of steel structures - Part 1-2: General rules - Structural fire design. Brussels: CEN - European Committee for Standardization (2005), pp. 78.

[13] CEN. EN 1992-1-2 - Eurocode 2: Design of concrete structures Part 1-2: General rules - Structural fire design. Brussels: CEN European Committee for Standardization (2004), pp. 97.

[14] Linus Lim, Andrew Buchanan, Peter Moss, Jean-Marc Franssen, "Numerical modelling of two-way reinforced concrete slabs in fire", Engineering Structures, Volume 26, Issue 8, , ISSN 0141-0296, https://doi.org/10.1016/j.engstruct.2004.03.009, (2004), pp. 10811091. 